\title{
Osmotic pressure, water kinetics and volatile fatty acid absorption in the rumen of sheep sustained by intragastric infusions
}

\author{
BY S. LÓPEZ*, F. D. DEB. HOVELL AND N. A. MACLEOD \\ Rowett Research Institute, Bucksburn, Aberdeen AB2 $9 S B$
}

(Received 9 November 1992 - Revised 8 February 1993-Accepted 18 March 1993)

\begin{abstract}
The effects of changing rumen osmotic pressure (OP) upon water kinetics and volatile fatty acid (VFA) absorption in the rumen of sheep were studied in two $4 \times 4$ Latin square experiments, each using four lambs with a rumen cannula and an abomasal catheter. In both experiments the lambs were sustained by the intragastric infusion of all nutrients (VFA, Ca, P, Mg and a buffer solution into the rumen, and casein, vitamins and trace elements into the abomasum). On experimental days, which were at least 1 week apart, drinking water and the casein infusion were withdrawn, and the ruminal $O P$ was changed and held constant for $9.5 \mathrm{~h}$, by incorporating $\mathrm{NaCl}$ at different concentrations in the buffer solution being infused. In Expt 1 the target OP values were 300, 340, 380 and $420 \mathrm{mosmol} / \mathrm{kg}$, and in Expt 2 were 261 (no saline addition), 350, 420 and $490 \mathrm{mosmol} / \mathrm{kg}$. Using soluble non-absorbable markers (PEG in continuous infusion and $\mathrm{Cr}$-EDTA injected in pulse doses) rumen volume, liquid outflow rates, apparent water absorption through the rumen wall and VFA absorption rates were estimated at six sampling times corresponding to the $1.5 \mathrm{~h}$ intervals during the last $7.5 \mathrm{~h}$ following the change in rumen OP. Liquid outflow rate $(F ; \mathrm{ml} / \mathrm{h})$ showed a significant and positive linear relationship with the rumen $O P$ (mosmol/kg), resulting in the equation $F=1.24 \mathrm{OP}$ (SE 0.096) - 36.5 (SE 36.6) $\left(r^{2} 0.96\right)$. Similarly, water absorption rate $(W ; \mathrm{ml} / \mathrm{h})$ was significantly affected by rumen $\mathrm{OP}$, and this relationship was given by $W=395$ (SE 39.9) -1.16 OP (SE 0.105) $\left(r^{2} 0.95\right)$, which means that for an OP of $341 \mathrm{mosmol} / \mathrm{kg}$ the net movement of water across the rumen wall would be zero, and either a net efflux or a net influx of water would be observed with lower or higher OP respectively. In Expt 2 there was a significant linear effect of OP on rumen volume $(P<0.01)$, with higher $O P$ being associated with increases in rumen liquid contents of about 10-20\%. As rumen $O P$ was increased there was also a decline in the absorption rate of VFA (from $232 \mathrm{mmol} V F A / h$ for OP 350 to $191 \mathrm{mmol} / \mathrm{h}$ for OP $490 \mathrm{mosmol} / \mathrm{kg}$ ), resulting in the accumulation of VFA (especially acetate) in the rumen and a consequent fall in rumen pH. Rumen $O P$ seems to be important in defining water movement across the rumen wall and, hence, partitioning between absorption and outflow.
\end{abstract}

Osmotic pressure: Rumen: Liquid outflow: Water absorption: VFA absorption: Sheep

In ruminants the mechanisms controlling water balance in the forestomachs can be important in the maintenance of water equilibrium and osmotic regulation in the body, since the rumen liquid volume and the daily flows of water into and out of the rumen can account for a high proportion of the total body water (Engelhardt, 1970). The pool size and turnover rate of water in this compartment depends on the balance between the input of water, mainly from water intake and saliva flow, and the passage rate of fluid from the reticulo-rumen into the omasum. The water exchange between the rumen contents and the plasma can occur in both directions, and the net movement of this water will define the balance in the rumen pool. Total water exchange across the epithelium is large and variable,

* Present address: Departamento de Producción Animal, Universidad de León, 24071 León, Spain. 
and can be important for the water distribution between the different pools in the body. The net movement of water through the rumen epithelium has been estimated using rumen pouches (Engelhardt, 1970), using the temporally washed and isolated rumen (Engelhardt, 1970), diverting the saliva via an oesophageal fistula in sheep fasting during the measurement period (Warner \& Stacy, 1972), and using labelled water (Faichney \& Boston, 1985). Although the net result of this flux may not be large, it can affect the fluid dilution rate in the rumen, and the partition of water loss from the rumen between absorption across the rumen wall, and outflow to the omasum and abomasum. The further effect would be on the rumen fermentation pattern, on the absorption of nutrients from the rumen and on the extent and composition of the daily flow of digesta from the reticulo-rumen. The main signal defining the transepithelial movement of water seems to be the osmotic gradient between the rumen contents and the plasma, which determines the extent and direction of the diffusion of water, and the blood flow in the rumen epithelium (Dobson et al. 1976).

The technique of intragastric nutrition by which ruminants can be sustained for long periods on continuous infusions (Ørskov et al. 1979) has the advantages that the use of soluble markers for the liquid phase of the rumen can be easier, and accurate estimates of the rumen volume and water kinetics can be obtained at several different times during the day. The infusion rates of water and nutrients are known exactly, and therefore it is possible to estimate their absorption. The variables defining rumen conditions can be manipulated, enabling one or more to be changed and held stable at a desired level for relatively long periods of time. Therefore, animals maintained by the intragastric infusion of nutrients can be appropriate models to enable study of the response of the animal when one factor is varied and controlled, without the interaction of other related factors.

The object of the work reported in the present paper was to study the effect of changing rumen osmotic pressure on the water kinetics in the rumen of sheep nourished by intragastric infusions. The variations in rumen liquid outflow, apparent water absorption and volatile fatty acid (VFA) absorption induced by the infusion of mineral salt $(\mathrm{NaCl})$ at different concentrations were assessed.

\section{MATERIALS AND METHODS}

Experimental design

Two experiments were conducted in which the rumen osmotic pressure (OP) was altered by the infusion of $\mathrm{NaCl}$ into the rumen. The design used in each experiment was a $4 \times 4$ (four animals and four experimental periods) Latin square, in which the animals were allocated at random to experimental treatments (four different target OP values). Four lambs fitted with a rumen cannula and an abomasal catheter were used in each trial, and were maintained by the intragastric infusion of nutrients. Each experimental period consisted of one experimental day. On that particular day the rumen OP was modified and the target OP imposed and held stable at each level for $9.5 \mathrm{~h}$. Meanwhile, markers for the liquid phase were dosed and samples were collected at different intervals. The animals then rested for at least 1 week before the next experimental period. The main differences between the experiments were the animals used and the treatments imposed. In Expt 1 the animals were four Suffolk cross-bred wether lambs aged about 10 months and weighing on average 34 (SE 1.1) kg live weight (LW), and the target rumen OP were 300, 340, 380 and $420 \mathrm{mosmol} / \mathrm{kg}$. In the second experiment four Finn Dorset $\times$ Suffolk female lambs $(8-10$ months old and 35 (SE 0.9) $\mathrm{kg} \mathrm{LW}$ ) were used, and the target OP were 260, 350, 420 and $490 \mathrm{mosmol} / \mathrm{kg}$. In treatment 260-OP (Expt 2), no $\mathrm{NaCl}$ was dosed or infused in the rumen, and the OP was that naturally observed when the animals were maintained at the basal level of VFA and buffer infusion. 


\section{Intragastric infusion of nutrients}

Details of the management of the intragastric infusions were as described by Hovell et al. (1987). After recovery from surgery, intragastric infusion of nutrients was introduced progressively during a 10-12 d adaptation period, solid food being withdrawn in the second half of this period. The lambs were kept in metabolism cages and nourished by an intraruminal infusion of a solution of VFA containing ( $\mathrm{mmol} / \mathrm{mol}$ total VFA): acetate 650 , propionate 250 and butyrate 100 , and macro-minerals $(\mathrm{Ca}, \mathrm{P}$ and $\mathrm{Mg}$ ), with a separate intraruminal infusion of a solution of McDougall buffer, and an intra-abomasal infusion of a casein solution, sufficient to provide about $600-650 \mathrm{~kJ}$ as VFA, and $600-700 \mathrm{mg}$ casein- $\mathrm{N} / \mathrm{kg} \mathrm{LW}{ }^{0.75}$ daily. Vitamins were mixed into the casein solution, and microminerals dosed per abomasum daily. At the end of the experiment, lambs were inoculated with rumen fluid from a normally-fed animal, reintroduced to solid food, and fed normally.

\section{Experimental procedures}

On experimental days the casein infusion was withdrawn, and access to drinking water was not allowed during the course of the experiment. The VFA solution as infused contained approximately 2.29 (Expt 1) 2.09 (Expt 2) mol total VFA/l (with $40 \mathrm{mmol} \mathrm{CaCO}_{3} / \mathrm{kg}$, $12 \mathrm{mmol} \mathrm{Ca}\left(\mathrm{H}_{2} \mathrm{PO}_{4}\right)_{2} . \mathrm{H}_{2} \mathrm{O} / \mathrm{kg}$ and $7.5 \mathrm{mmol} \mathrm{MgCl}_{2} \cdot 6 \mathrm{H}_{2} \mathrm{O} / \mathrm{kg}$ to supply macro-minerals), and the buffer solution about $170 \mathrm{mmol} \mathrm{NaHCO}_{3} / \mathrm{kg}, 75 \mathrm{mmol} \mathrm{KHCO}_{3} / \mathrm{kg}$ and $25 \mathrm{mmol}$ $\mathrm{NaCl} / \mathrm{kg}$. VFA solution was infused at 137 (SE 1.9) and 128 (SE 1.7) $\mathrm{ml} / \mathrm{h}$, and the buffer solution at 249 (SE 5.9) and 259 (SE 4.1$) \mathrm{ml} / \mathrm{h}$ in Expts 1 and 2 respectively, giving overall infusion rates of $386\left(\mathrm{SE} 7 \cdot 1\right.$ ) and 387 (SE 4.7) $\mathrm{ml}$ liquid/h (i.e. about $0.65 \mathrm{l} / \mathrm{kg} \mathrm{LW}^{0.75}$ per d). Polyethylene glycol (PEG) was included in both rumen infusates at a concentration of $1 \mathrm{~g} / \mathrm{l}$, initiating its continuous infusion $3 \mathrm{~d}$ before the day the OP was manipulated, in order to have a stable level of PEG in the rumen contents. The marker used to estimate rumen volume was Cr-EDTA prepared as described by Downes \& McDonald (1964), and injected directly into the rumen via the cannula as pulse doses at each sampling time.

In order to change the rumen $\mathrm{OP}, \mathrm{NaCl}$ was incorporated at different concentrations (depending on the treatment) in the buffer solution, so saline was continuously infused with the aim of getting a stable level of OP in the rumen. To raise the rumen OP as rapidly as possible, small pulse doses of $\mathrm{NaCl}$ solution $(100 \mathrm{~g} / \mathrm{l})$ were injected during the first 30-45 min, and then occasionally during the course of the experiment as required. A solution of buffer without $\mathrm{NaCl}$ was kept for each animal, and the infusion tubes for the buffer were switched between solutions as required so as to keep the OP as close to the target OP as possible. Rumen OP was monitored every 5-30 min (depending on stability) to determine whether a dose of saline or a change in the $\mathrm{NaCl}$ infusion was required.

Before starting the salt infusion ( $\mathrm{T} 0$ ), samples were taken from the rumen and the abomasal catheter. Samples were also withdrawn after $2 \mathrm{~h}$ (T1) to get a first stable level of OP, and thereafter every $1.5 \mathrm{~h}$ (at $3 \cdot 5,5,6 \cdot 5,8$ and $9 \cdot 5 \mathrm{~h}$ (T2-T6) after the change in OP began). The infusion was then stopped, free access to drinking water was allowed, and the rumen contents were emptied and replaced with warm water. The $\mathrm{pH}$ and $\mathrm{OP}$ were monitored during the next $46 \mathrm{~h}$, and the VFA and buffer infusions were resumed at low levels after 5-10 h. During the next $2 \mathrm{~d}$, and depending on the recovery of each animal, the VFA and buffer infusions were increased up to the basal level of infusion.

Sampling of rumen fluid was carried out as follows. Firstly a rumen sample was taken with a syringe, then the Cr-EDTA was injected into the rumen through the cannula and the rumen contents were thoroughly mixed by pumping rumen liquid in and out with a $60 \mathrm{ml}$ syringe for not less than $3 \mathrm{~min}$. A second rumen sample was then withdrawn, and finally a sample of abomasal liquid was taken from the catheter normally used to infuse casein. 
As the samples were collected, their $\mathrm{pH}$ and $\mathrm{OP}$ were determined. They were then centrifuged at $3000 \mathrm{rev} . / \mathrm{min}$ for $15 \mathrm{~min}$ and the supernatant fraction was frozen at $-18^{\circ}$ and retained for subsequent analyses. In Expt 2, before freezing, the $4 \mathrm{ml}$ supernatant fraction was acidified with $1 \mathrm{ml} 20$ mm-ethylbutyric acid in meta-phosphoric acid $(250 \mathrm{~g} / \mathrm{l})$ and stored at $4^{\circ}$ for subsequent VFA analysis. In Expt 1, urine samples were collected at each sampling time and their $\mathrm{pH}$ and $\mathrm{OP}$ were measured. Also in Expt 1, and at the beginning and end of each experimental period, blood samples were taken from the jugular vein and were centrifuged to determine OP and total solids composition in plasma.

\section{Analytical methods}

$\mathrm{pH}$ was measured directly with a $\mathrm{pH}$ meter and $\mathrm{OP}$ was determined with an osmometer based on the depression in the critical freezing point. PEG concentration was determined by the turbidity method described by Hydén (1956), using a spectrophotometer to measure absorbance at $650 \mathrm{~nm}$. Cr concentration in the rumen samples was analysed by atomic absorption spectrophotometry at a wavelength of $357.9 \mathrm{~nm}$ using an air-acetylene flame. VFA concentration and molar proportions were determined (only in Expt 2) by GLC with flame-ionization detector, using ethylbutyric acid as the internal standard (Ottenstein \& Bartley, 1971). Total solids composition in plasma (TS; $\mathrm{g} / \mathrm{kg}$ ) were measured using a TS meter (Goldberg refractometer).

\section{Calculations}

Rumen liquid kinetics. Rumen volume $\left(V_{t}, 1\right)$ was estimated as

$$
V_{t}=\frac{D}{\left(C^{+}-C^{-}\right)}
$$

where $D(\mathrm{mg} \mathrm{Cr})$ is the pulse dose at time $t$ and $C^{-}$and $C^{+}$(both $\mathrm{mg} \mathrm{Cr} / \mathrm{l}$ ) are the ruminal concentrations of $\mathrm{Cr}$ at time $t$ immediately before and after dosing respectively.

In normally-fed animals $C^{+}$cannot be determined directly, because mixing is slow. However, in these animals it is easy to mix the liquid content of the rumen after dosing by repetitively removing and returning some rumen liquid using a $60 \mathrm{ml}$ syringe. Indeed in a pilot trial in which we determined the Cr-EDTA both immediately after dosing, and $10 \mathrm{~min}$ later, we were able to detect a slight reduction in Cr-EDTA concentration, presumably due to outflow.

Fractional outflow rate $(k ; / h)$ was calculated as

$$
k=\frac{I_{P E G}}{P E G_{t} V_{t}}
$$

where $I_{\mathrm{PEG}}(\mathrm{mg} / \mathrm{h})$ is the rate of infusion of $\mathrm{PEG}$ and $P E G_{t}(\mathrm{mg} / \mathrm{l})$ is its ruminal concentration at time $t$. For the average outflow rate $(F ; \mathrm{ml} / \mathrm{h})$ between two consecutive sampling times, the ensuing relation was used (Warner \& Stacy, 1968),

$$
F=\frac{I_{P E G}}{\overline{P E G}}
$$

where $\overline{P E G}$ is the average $\mathrm{PEG}$ concentration $(\mathrm{mg} / \mathrm{ml})$.

Let $I(\mathrm{ml} / \mathrm{h})$ be the rate of infusion of water in the rumen, then the apparent water absorption through the rumen wall $(W ; \mathrm{ml} / \mathrm{h})$ was estimated as

$$
W=I-F \text {. }
$$

If $W$ is positive, then there is a net absorption of water into the plasma. Negative values of $W$ indicate that there is a net inflow of water into the rumen coming either from saliva 
flow or from the movement of water across the rumen wall. Although in animals receiving a continuous infusion of nutrients the production of saliva is presumably low, it is not possible to derive the contribution of each source to the estimated overall net inflow of liquid.

The model assumes that the rumen pool of PEG is in steady state at the time of sampling, as has been described in detail by Warner \& Stacy (1968) and France et al. (1991).

$V F A$ absorption. As the supply of VFA to the rumen is exactly known, it is possible to estimate the VFA absorption rate $(A ; \mathrm{mmol} / \mathrm{h})$ assuming that the VFA concentration $\left(C_{V F A} ; \mathrm{mmol} / \mathrm{ml}\right)$ of the liquid leaving the rumen is the same as the mean VFA concentration of the rumen contents. Then,

$$
A=I_{V F A}-F \overline{C_{V F A}} \text {, }
$$

where $I_{V F A}(\mathrm{mmol} / \mathrm{h})$ is the VFA infusion rate, $F(\mathrm{ml} / \mathrm{h})$ is the liquid outflow rate and $\overline{C_{V F A}}$ is the average VFA concentration between both sampling times.

This model also assumes that the rumen pool of VFA is in steady state at the time of sampling.

\section{Statistical analysis}

Data were examined by ANOVA using Latin square designs, considering the sequential samples during the day as repeated observations on each experimental unit. Linear and quadratic effects of the level of OP were separated by orthogonal polynomials. In the same way, the effect of the sampling time was examined by analysis of orthogonal contrasts over time (Rowell \& Walters, 1976). Statistical dependence between variables was established by simple linear correlation and regression analyses.

\section{RESULTS}

Osmotic pressure and $\mathrm{NaCl}$ dosing

The target OP and the OP achieved are shown in Table 1. This table also contains the values of the OP observed before any saline dosing began. OP was held reasonably close to the targeted values in each experimental treatment and in both experiments. In Expt 2, treatment 260-OP represents the situation where no $\mathrm{NaCl}$ was dosed or infused, and the OP was that naturally achieved at that level of infusion with these animals. The observed OP for each treatment are given with their corresponding standard deviations which are derived from the total within-treatment variance, and were calculated from the OP recorded at the sampling times, but do not include the multiple OP measurements taken between samples when saline was dosed as necessary to achieve the desired OP. This variance never accounted for more than $8 \%$ of the means, and analysis of variance showed no significant differences between times or between animals $(P>0 \cdot 10)$, so once the OP had been raised by small pulse doses the observed OP conformed reasonably to the targeted values and were held constant.

The average rate of $\mathrm{NaCl}$ dosing is also shown in Table 1. The values given represent the total of that infused and that dosed directly into the rumen. The relative amount of $\mathrm{NaCl}$ required in the two experiments was very similar, and treatment means fitted the simple linear relationship OP (mosmol $/ \mathrm{kg})=260($ SE 5$)+19($ SE 0.7$) ~ \mathrm{NaCl}(\mathrm{g} / \mathrm{h})(r 0.99, n$ 8). It should be noted that the good agreement between experiments in the amount of $\mathrm{NaCl}$ necessary was in a situation where the basal rates of VFA and buffer infusion in the two experiments were almost identical (see pp. 156-157).

\section{Water kinetics}

There were no significant effects of experimental period either on the observed rumen OP or on any of the variables studied in both experiments. 
Table 1. Initial, target and achieved (observed) osmotic pressure (OP; mosmol $/ \mathrm{kg}$ ) in sheep rumen infused with different concentrations of saline*

\begin{tabular}{|c|c|c|c|c|c|c|}
\hline & & & & & & $\mathrm{SE}$ \\
\hline \multirow[t]{5}{*}{ Expt 1} & Initial $\mathrm{OP} \uparrow$ & 261 & 267 & 283 & 271 & \multirow[t]{5}{*}{$4 \cdot 4$} \\
\hline & Target OP & 300 & 340 & 380 & 420 & \\
\hline & Observed OP+ Mean & 307 & 340 & 381 & 419 & \\
\hline & SD & $24 \cdot 2$ & $5 \cdot 5$ & 6.5 & 6.4 & \\
\hline & $\mathrm{NaCl}$ dose $(\mathrm{g} / \mathrm{h})$ & $2 \cdot 35$ & 4.85 & $6 \cdot 10$ & 8.08 & \\
\hline \multirow[t]{5}{*}{ Expt 2} & Initial OP & 268 & 262 & 259 & 270 & \multirow[t]{5}{*}{$7 \cdot 0$} \\
\hline & Target $\mathrm{OP}$ & $261 \S$ & 350 & 420 & 490 & \\
\hline & Observed OP+: Mean & 261 & 356 & 425 & 499 & \\
\hline & SD & $19 \cdot 4$ & $8 \cdot 1$ & $13 \cdot 5$ & $23 \cdot 7$ & \\
\hline & $\mathrm{NaCl}$ dose $(\mathrm{g} / \mathrm{h})$ & nil & $5 \cdot 30$ & $8 \cdot 16$ & $12 \cdot 78$ & \\
\hline
\end{tabular}

* For details of animals and procedures, see pp. 154-156.

$\dagger$ Means of four lambs in each experiment.

+ Means of four lambs in each experiment with six observations (sampling times) on each animal.

$\S$ In Expt 2 the target OP for the lowest treatment was the base OP with no NaCl dosing.

Table 2. The effect of changing rumen osmotic pressure $(O P ;$ mosmol/kg) on rumen volume $(l)$ in sheep

\begin{tabular}{|c|c|c|c|c|c|c|c|c|c|c|}
\hline & \multirow[b]{2}{*}{ Treatment $\dagger$} & \multirow{2}{*}{$\begin{array}{c}\text { Initial } \\
\text { Volume }\end{array}$} & \multicolumn{6}{|c|}{ Time* } & \multirow[b]{2}{*}{ Mean } & \multirow{2}{*}{$\begin{array}{l}\text { Average } \\
\text { relative } \\
\text { change }\end{array}$} \\
\hline & & & $\mathrm{Tl}$ & $\mathrm{T} 2$ & $\mathrm{~T} 3$ & $\mathrm{~T} 4$ & T5 & T6 & & \\
\hline \multirow[t]{4}{*}{ Expt 1} & $300-\mathrm{OP}$ & $3 \cdot 98$ & $3 \cdot 97$ & $4 \cdot 22$ & 3.93 & 3.97 & 3.66 & 3.92 & 3.94 & -0.033 \\
\hline & $340-\mathrm{OP}$ & $4 \cdot 29$ & $4 \cdot 75$ & $5 \cdot 16$ & $4 \cdot 74$ & $4 \cdot 74$ & $5 \cdot 18$ & $5 \cdot 12$ & 4.95 & +0.660 \\
\hline & 380-OP & 3.95 & $4 \cdot 48$ & $4 \cdot 83$ & $4 \cdot 50$ & 4.90 & $4 \cdot 30$ & $4 \cdot 78$ & $4 \cdot 63$ & +0.679 \\
\hline & $420-\mathrm{OP}$ & 4.01 & $4 \cdot 55$ & 4.97 & 4.94 & $5 \cdot 23$ & $4 \cdot 81$ & 4.96 & 4.91 & +0.902 \\
\hline SEł & & 0.294 & & & & & & & 0.257 & 0.222 \\
\hline \multirow[t]{4}{*}{ Expt 2} & $260-\mathrm{OP}$ & 3.94 & $3 \cdot 93$ & $4 \cdot 21$ & $4 \cdot 44$ & $3 \cdot 67$ & $3 \cdot 80$ & $3 \cdot 77$ & $3.97^{\mathrm{ab}}$ & +0.028 \\
\hline & 350-OP & $4 \cdot 18$ & $4 \cdot 18$ & $4 \cdot 12$ & 4.09 & 3.57 & $4 \cdot 02$ & 3.64 & $3 \cdot 94^{\mathrm{a}}$ & -0.242 \\
\hline & $420-\mathrm{OP}$ & $4 \cdot 08$ & $5 \cdot 01$ & $4 \cdot 86$ & $5 \cdot 02$ & $4 \cdot 18$ & $4 \cdot 26$ & $4 \cdot 51$ & $4 \cdot 64$ & +0.565 \\
\hline & $490-\mathrm{OP}$ & $4 \cdot 64$ & 5.01 & $5 \cdot 24$ & $5 \cdot 35$ & 4.69 & 4.94 & $5 \cdot 39$ & $5 \cdot 10^{\circ}$ & +0.464 \\
\hline $\mathrm{SE}_{+}^{\dagger}$ & & $0 \cdot 223$ & & & & & & & $0 \cdot 199$ & $0 \cdot 255$ \\
\hline
\end{tabular}

a.b." Within each experiment, means with unlike superscripts are significantly different $(P<0.05)$.

* T1 was at $2 \mathrm{~h}$, and $\mathrm{T} 2$ to $\mathrm{T} 6$ at $3 \cdot 5,5,6 \cdot 5,8$ and $9 \cdot 5 \mathrm{~h}$ respectively after initiating the change in rumen $O P$.

$\dagger$ For details of treatments, see Table 1 and pp. 154-156.

† Standard errors of the means for comparisons between treatments. For comparisons between times within each treatment, SE were 0.236 and 0.208 in Expts 1 and 2 respectively.

Rumen volume. Rumen fluid volumes in both experiments, and for all sampling times, together with their overall means are shown in Table 2. In Expt 1 there was no significant effect either of OP or time on rumen volume. There was, however, the suggestion that the higher OP values were associated with increases in rumen volume. In Expt 2 the linear effect of OP was significant $(P<0 \cdot 01)$, the rumen volume being greater with higher rumen OP. In both experiments changes in rumen volume, when these occurred, were complete by $3.5 \mathrm{~h}$ after initiating the change in OP (T2). In Expt 2, volumes at later times after changing OP tended to be slightly lower, with the result that the linear effect of time was statistically significant $(P<0.01)$ with a negative slope. However, this slope was not statistically 
Table 3. The effect of changing rumen osmotic pressure $(O P ;$ mosmol/kg) on rumen water kinetics in sheep

\begin{tabular}{|c|c|c|c|c|c|c|c|c|c|c|}
\hline & \multirow[b]{3}{*}{ Treatment $\dagger$} & \multirow{3}{*}{$\begin{array}{l}\text { Mean } \\
\text { fractional } \\
\text { outflow } \\
\text { rate } \\
(/ \mathrm{h})\end{array}$} & \multicolumn{7}{|c|}{ Liquid outflow rate $(\mathrm{ml} / \mathrm{h})$} & \multirow{3}{*}{$\begin{array}{c}\text { Water } \\
\text { absorption } \\
(\mathrm{ml} / \mathrm{h})\end{array}$} \\
\hline & & & \multicolumn{6}{|c|}{ Time* } & \multirow[b]{2}{*}{ Mean } & \\
\hline & & & $\mathrm{T} 1$ & $\mathrm{~T} 2$ & T3 & $\mathrm{T} 4$ & $\mathrm{~T} 5$ & T6 & & \\
\hline \multirow[t]{4}{*}{ Expt 1} & $300-\mathrm{OP}$ & 0.0879 & 359 & 363 & 356 & 348 & 345 & 345 & $352 \cdot 5$ & $18 \cdot 2$ \\
\hline & $340-\mathrm{OP}$ & 0.0920 & 407 & 422 & 418 & 388 & 387 & 425 & $407 \cdot 9$ & $-21 \cdot 1$ \\
\hline & $380-\mathrm{OP}$ & $0 \cdot 0992$ & 389 & 402 & 422 & 437 & 455 & 473 & $429 \cdot 9$ & $-22 \cdot 6$ \\
\hline & $420-\mathrm{OP}$ & 0.0981 & 404 & 435 & 460 & 461 & 470 & 458 & $448 \cdot 2$ & $-69 \cdot 0$ \\
\hline $\mathrm{SE}_{4}^{+}$ & & $0 \cdot 00587$ & & & & & & & $35 \cdot 36$ & $40 \cdot 47$ \\
\hline \multirow[t]{4}{*}{ Expt 2} & $260-\mathrm{OP}$ & $0 \cdot 0715^{\mathrm{a}}$ & 281 & 281 & 284 & 286 & 280 & 276 & $281 \cdot 5^{\mathrm{A}}$ & $93 \cdot 4^{\mathrm{a}}$ \\
\hline & $350-\mathrm{OP}$ & $0 \cdot 1008^{a b}$ & 389 & 398 & 399 & 397 & 399 & 407 & $398 \cdot 2^{b}$ & $-7 \cdot 2^{a b}$ \\
\hline & $420-\mathrm{OP}$ & $0 \cdot 1092^{\mathrm{h}}$ & 456 & 466 & 491 & 516 & 516 & 508 & $492 \cdot 2^{\prime}$ & $-102 \cdot 8^{\mathrm{hc}}$ \\
\hline & 490-OP & $0 \cdot 1245^{b}$ & 541 & 586 & 611 & 635 & 622 & 597 & $598 \cdot 7^{d}$ & $-206 \cdot 3^{\circ}$ \\
\hline SE & & $0 \cdot 00888$ & & & & & & & $26 \cdot 93$ & $31 \cdot 40$ \\
\hline
\end{tabular}

a. b. ‘. W Within each experiment, means with unlike superscripts are significantly different $(P<0 \cdot 05)$.

$\mathrm{T} 1$ was at $2 \mathrm{~h}$, and $\mathrm{T} 2$ to $\mathrm{T} 6$ at $3 \cdot 5,56 \cdot 5,8$ and $9 \cdot 5 \mathrm{~h}$ respectively after initiating the change in rumen OP.

$\dagger$ For details of treatments, see Table 1 and pp. 154-156.

\$ Standard errots of the means for comparisons between treatments. For comparisons between times within each treatment, SE were 14.59 and 10.58 in Expts 1 and 2 respectively.

different from zero and taking the two experiments together there was no clear or consistent trend with time. The effect on rumen volume is also expressed as the change in rumen volume relative to the initial volume. Expressed in this way there was a clear tendency for the higher rumen OP to be associated with a 10-20\% increase in rumen volume. However, the large errors meant that the differences were not always statistically significant.

Liquid outflow and water absorption. Rumen liquid outflows are shown in Table 3, the data being expressed both as fractional and absolute outflow rates. Apparent water absorption calculated as the difference between infusion rate and outflow rate is also presented. In both experiments, increased OP was associated with greater rumen outflows when expressed as rates or as absolute flows. Despite this trend, in Expt 1 the differences between treatments in liquid outflow rate did not reach statistical significance. The linear relationship of outflow with OP was highly significant in Expt $2(P<0.001)$. The linear effect of time after changing OP on absolute outflow was highly significant in both experiments $(P<0.001)$. However, there was also a significant treatment $\times$ time interaction in both experiments (Expt $1 P<0.05$; Expt $2 P<0 \cdot 01$ ). For OP at $350 \mathrm{mosmol} / \mathrm{kg}$ or below, outflow changed little with time, whereas with OP above $350 \mathrm{mosmol} / \mathrm{kg}$ the change was more evident and outflows tended to increase during the day. In Expt 2 this pattern was combined with a significant quadratic effect $(P<0.001)$; with the higher OP, outflow reached a maximum after $6.5 \mathrm{~h}$ (T4).

Since water infusion rate into the rumen was constant, a similar but inverse relationship was observed in the apparent water absorption. Rumen OP significantly $(P<0 \cdot 001)$ affected the net movement of water across the rumen epithelium, determining both its extent and direction. So, with the lower OP values there was some net absorption of water across the rumen wall, but when OP was $340 \mathrm{mosmol} / \mathrm{kg}$ or greater, there was a net influx of water to the rumen (shown as a negative absorption) coming either from saliva flow, or 
Table 4. The effect of changing rumen osmotic pressure $(O P ;$ mosmol/kg) on rumen $p H$ in sheep

\begin{tabular}{|c|c|c|c|c|c|c|c|c|c|}
\hline & \multirow[b]{2}{*}{ Treatment $\dagger$} & \multirow[b]{2}{*}{ Initial $\mathrm{pH}$} & \multicolumn{6}{|c|}{ Time* } & \multirow[b]{2}{*}{ Mean } \\
\hline & & & $\mathrm{Tl}$ & $\mathrm{T} 2$ & $\mathrm{~T} 3$ & $\mathrm{~T} 4$ & $\mathrm{~T} 5$ & T6 & \\
\hline \multirow[t]{4}{*}{ Expt 1} & $300-O P$ & 6.44 & 6.20 & $6 \cdot 18$ & $6 \cdot 18$ & 6.15 & $6 \cdot 20$ & 6.03 & $6 \cdot 15^{b}$ \\
\hline & 340-OP & $6 \cdot 23$ & $6 \cdot 10$ & $6 \cdot 18$ & 6.03 & 5.98 & 5.98 & 5.95 & $6.03^{D}$ \\
\hline & $380-\mathrm{OP}$ & $6 \cdot 24$ & 5.93 & 5.88 & $5 \cdot 73$ & $5 \cdot 78$ & $5 \cdot 75$ & $5 \cdot 78$ & $5 \cdot 80^{4}$ \\
\hline & $420-\mathrm{OP}$ & $6 \cdot 34$ & 5.93 & 5.78 & 5.60 & $5 \cdot 70$ & $5 \cdot 65$ & 5.57 & $5 \cdot 70^{\mathrm{a}}$ \\
\hline $\mathrm{SE}_{+}^{+}$ & & 0.079 & & & & & & & 0.039 \\
\hline \multirow[t]{4}{*}{ Expt 2} & $260-\mathrm{OP}$ & $6 \cdot 31$ & $6 \cdot 25$ & $6 \cdot 24$ & $6 \cdot 20$ & 6.08 & 6.09 & 6.00 & $6 \cdot 14^{\prime}$ \\
\hline & $350-\mathrm{OP}$ & $6 \cdot 13$ & $5 \cdot 80$ & 5.73 & $5 \cdot 68$ & $5 \cdot 72$ & $5 \cdot 59$ & $5 \cdot 62$ & $5 \cdot 69^{\mathrm{b}}$ \\
\hline & $420-\mathrm{OP}$ & 6.02 & $5 \cdot 61$ & 5.56 & $5 \cdot 50$ & $5 \cdot 62$ & $5 \cdot 50$ & $5 \cdot 50$ & $5 \cdot 55^{\mathrm{ah}}$ \\
\hline & $490-\mathrm{OP}$ & 5.97 & $5 \cdot 35$ & $5 \cdot 22$ & $5 \cdot 19$ & $5 \cdot 10$ & $5 \cdot 10$ & 5.08 & $5 \cdot 17^{i 2}$ \\
\hline $\mathrm{SE}_{+}^{+}$ & & $0 \cdot 106$ & & & & & & & 0.129 \\
\hline
\end{tabular}

a. h. Within each experiment, means with unlike superscripts are significantly different $(P<0 \cdot 05)$.

* T1 was at $2 \mathrm{~h}$, and T2 to T6 at $3 \cdot 5,5,6 \cdot 5,8$ and $9 \cdot 5 \mathrm{~h}$ respectively after initiating the change in rumen OP.

$\dagger$ For details of treatments, see Table 1 and pp. 154-156.

¥ Standard errors of the means for comparisons between treatments. For comparisons between times within each treatment, SE were 0.045 and 0.046 in Expts 1 and 2 respectively.

directly from the plasma across the rumen wall. The linear relationship of trans-epithelial water flux with OP was statistically significant in Expt $2(P<0.001)$.

\section{Rumen $p H$}

Rumen $\mathrm{pH}$ values are given in Table 4 . In both experiments rumen $\mathrm{pH}$ decreased linearly $(P<0.001)$ as OP increased, and within each treatment a significant $(P<0.001)$ linear decline in rumen $\mathrm{pH}$ with time was observed. Although there was the suggestion of an interaction (i.e. higher OP being associated with greater decline of rumen $\mathrm{pH}$ with time), this did not reach statistical significance in either experiment $(P>0.05)$.

\section{Expt 2.VFA concentration and molar proportions in the rumen}

The change in rumen OP did not significantly affect $(P>0 \cdot 10)$ VFA concentrations in the rumen, although values tended to be higher with higher OP (Table 5). There was no effect of time on rumen VFA concentrations $(P<0 \cdot 10)$, any changes from the initial concentration being complete by $3.5 \mathrm{~h}$ after initiating the change in OP (T2). The linear effect of OP on the molar proportions of VFA approached or reached significance $(P<$ $0 \cdot 05$ ), with a tendency for there to be higher proportions of acetic acid with lower propionic and butyric acid proportions as OP was increased. Although the interaction between treatment and time on VFA proportions was not statistically significant $(P>0.05)$, the changes in VFA proportions were cumulative during the course of the experiment. The differences in VFA proportions between treatments tended to increase with time, since the increase in the proportion of acetic acid and the decrease in the proportions of propionic and butyric acids associated with the increase in $\mathrm{OP}$ were greater for the later sampling times after changing OP.

\section{Expt 2. VFA absorption}

The calculated VFA absorption rates are presented in Table 6 . There was a significant effect of OP on VFA absorption rate $(P<0.05)$, with both a linear and a quadratic response to $\mathrm{OP}$. Absorption rate was always highest at $350-\mathrm{OP}$, and for higher OP there was a linear 
Table 5. Expt 2. Effect of changing rumen osmotic pressure $(O P ;$ mosmol $/ \mathrm{kg}$ ) on the ruminal concentration of total volatile fatty acids $(V F A ; m M)$ and on the molar proportions of acetic, propionic and butyric acids (mmol/mol total VFA) in sheep

\begin{tabular}{|c|c|c|c|c|c|c|c|c|c|c|}
\hline & & \multirow[b]{2}{*}{ Treatment ${ }^{\dagger}$} & \multirow{2}{*}{$\begin{array}{l}\text { Initial } \\
\text { values }\end{array}$} & \multicolumn{6}{|c|}{ Time* } & \multirow[b]{2}{*}{ Mean } \\
\hline & & & & $\mathrm{T} 1$ & $\mathrm{~T} 2$ & $\mathrm{~T} 3$ & $\mathrm{~T} 4$ & T5 & T6 & \\
\hline Total VFA & SE & $\begin{array}{l}260-\mathrm{OP} \\
350-\mathrm{OP} \\
420-\mathrm{OP} \\
490-\mathrm{OP}\end{array}$ & $\begin{array}{l}109 \\
100 \\
106 \\
118 \\
9 \cdot 9\end{array}$ & $\begin{array}{r}109 \\
99 \\
117 \\
134\end{array}$ & $\begin{array}{l}110 \\
114 \\
117 \\
129\end{array}$ & $\begin{array}{l}111 \\
107 \\
118 \\
126\end{array}$ & $\begin{array}{l}111 \\
108 \\
118 \\
123\end{array}$ & $\begin{array}{l}112 \\
114 \\
120 \\
129\end{array}$ & $\begin{array}{l}115 \\
113 \\
122 \\
129\end{array}$ & $\begin{array}{c}111 \\
109 \\
119 \\
129 \\
9.7\end{array}$ \\
\hline Acetic acid & SE† & $\begin{array}{l}260-O P \\
350-O P \\
420-O P \\
490-O P\end{array}$ & $\begin{array}{l}670 \\
652 \\
662 \\
683 \\
14 \cdot 8\end{array}$ & $\begin{array}{l}672 \\
649 \\
681 \\
714\end{array}$ & $\begin{array}{l}678 \\
680 \\
693 \\
730\end{array}$ & $\begin{array}{l}680 \\
673 \\
706 \\
742\end{array}$ & $\begin{array}{l}678 \\
672 \\
706 \\
747\end{array}$ & $\begin{array}{l}681 \\
669 \\
707 \\
736\end{array}$ & $\begin{array}{l}678 \\
683 \\
705 \\
750\end{array}$ & $\begin{array}{l}678^{a b} \\
671^{a} \\
700^{a b} \\
736^{b} \\
17 \cdot 6\end{array}$ \\
\hline Propionic acid & $\mathrm{SE}_{+}^{+}$ & $\begin{array}{l}260-\mathrm{OP} \\
350-\mathrm{OP} \\
420-\mathrm{OP} \\
490-\mathrm{OP}\end{array}$ & $\begin{array}{l}236 \\
261 \\
244 \\
230 \\
14 \cdot 3\end{array}$ & $\begin{array}{l}236 \\
266 \\
240 \\
219\end{array}$ & $\begin{array}{l}233 \\
242 \\
236 \\
211\end{array}$ & $\begin{array}{l}233 \\
250 \\
228 \\
201\end{array}$ & $\begin{array}{l}234 \\
251 \\
226 \\
198\end{array}$ & $\begin{array}{l}233 \\
248 \\
224 \\
200\end{array}$ & $\begin{array}{l}233 \\
240 \\
227 \\
194\end{array}$ & $\begin{array}{l}233^{\mathrm{ah}} \\
249^{\mathrm{h}} \\
230^{\mathrm{ah}} \\
204^{\mathrm{a}} \\
11 \cdot 7\end{array}$ \\
\hline Butyric acid & $\mathrm{SE}+$ & $\begin{array}{l}260-\mathrm{OP} \\
350-\mathrm{OP} \\
420-\mathrm{OP} \\
490-\mathrm{OP}\end{array}$ & $\begin{array}{l}91 \\
86 \\
92 \\
83 \\
4.5\end{array}$ & $\begin{array}{l}90 \\
84 \\
77 \\
65\end{array}$ & $\begin{array}{l}87 \\
76 \\
69 \\
58\end{array}$ & $\begin{array}{l}86 \\
78 \\
66 \\
56\end{array}$ & $\begin{array}{l}85 \\
77 \\
66 \\
54\end{array}$ & $\begin{array}{l}84 \\
82 \\
67 \\
63\end{array}$ & $\begin{array}{l}85 \\
75 \\
66 \\
56\end{array}$ & $\begin{array}{l}86^{\mathrm{b}} \\
79^{\mathrm{ath}} \\
69^{\mathrm{ab}} \\
59^{\mathrm{a}} \\
6 \cdot 0\end{array}$ \\
\hline
\end{tabular}

a.h Within each parameter, means with unlike superscripts are significantly different $(P<0.05)$.

* T1 was at $2 \mathrm{~h}$, and $\mathrm{T} 2$ to $\mathrm{T} 6$ at $3 \cdot 5,5,6 \cdot 5,8$ and $9 \cdot 5 \mathrm{~h}$ respectively after initiating the change in rumen OP.

$\dagger$ For details (Expt 2), see Table 1 and pp. 154-156.

₹ Standard errors of the means for comparisons between treatments. For comparisons between times within each treatment, SE were 3.30 for total VFA and $6 \cdot 1,4 \cdot 6$ and $2 \cdot 1$ for the molar proportions of acetic, propionic and butyric acids respectively.

Table 6. Expt 2. The effect of rumen osmotic pressure $(O P ;$ mosmol $/ \mathrm{kg})$ on volatile fatty acid (VFA) absorption (mmol/h), and on the relative rates of absorption of acetic, propionic and butyric acids ( $\mathrm{mmol} / \mathrm{mol}$ ) in sheep

\begin{tabular}{|c|c|c|c|c|c|c|c|c|c|c|}
\hline \multirow[b]{3}{*}{ Treatment $\uparrow$} & \multirow{2}{*}{\multicolumn{6}{|c|}{ Time* }} & \multirow[b]{3}{*}{ Mean } & \multicolumn{3}{|c|}{$\begin{array}{c}\text { Mean molar proportions } \\
\text { of VFA absorbed }\end{array}$} \\
\hline & & & & & & & & Acetic & Pronionic & Butyric \\
\hline & $\mathrm{T} 1$ & $\mathrm{~T} 2$ & $\mathrm{~T} 3$ & $\mathrm{~T} 4$ & T5 & T6 & & acid & acid & acid \\
\hline 260-OP & 220 & 220 & 219 & 219 & 220 & 220 & $219 \cdot 7^{b}$ & 644 & 253 & 103 \\
\hline $350-\mathrm{OP}$ & 237 & 233 & 231 & 232 & 231 & 239 & $232 \cdot 1^{\mathrm{b}}$ & 647 & 249 & 104 \\
\hline 420-OP & 224 & 221 & 218 & 215 & 214 & 213 & $217 \cdot 5^{\mathrm{b}}$ & 637 & 255 & 109 \\
\hline 490-OP & 199 & 190 & 190 & 190 & 188 & 191 & $191 \cdot 5^{\mathrm{a}}$ & 613 & 270 & 118 \\
\hline $\mathrm{SE} \ddagger$ & & & & & & & $7 \cdot 42$ & & & \\
\hline
\end{tabular}

a.b Means with unlike superscripts are significantly different $(P<0.05)$

* TI was at $2 \mathrm{~h}$, and $\mathrm{T} 2$ to $\mathrm{T} 6$ at $3 \cdot 5,5,6 \cdot 5,8$ and $9 \cdot 5 \mathrm{~h}$ respectively after initiating the change in rumen $O P$

$\dagger$ For details (Expt 2), see Table 1 and pp. 154-156.

\$ Standard errors of the means for comparisons between treatments. For comparisons between times within each treatment, SE was $1 \cdot 73$. 
decline in the VFA absorption rate as OP was increased. The mean molar proportions of VFA absorbed are also shown, and reflect the changes in relative rumen concentrations (as the reciprocal), indicating that the relative rate of acetate absorption would decline, and those of propionate and of butyrate would increase as OP was increased. The rate of VFA absorption declined linearly with time $(P<0.001)$. The interaction term of time with OP was also significant $(P<0.01)$, with the $350-\mathrm{OP}$ and $420-\mathrm{OP}$ treatments showing a clear time effect, the $260-\mathrm{OP}$ remaining stable, and the 490-OP treatment remaining low throughout the experiment, with no obvious time-related effect.

\section{Expt 1. Urine and plasma}

Urine $\mathrm{pH}$ was not affected by time or treatment. Urine OP immediately rose from values close to $375 \mathrm{mosmol} / \mathrm{kg}$ to values close to $600 \mathrm{mosmol} / \mathrm{kg}$ but there were no effects of time or treatment on the extent of this increase. Plasma samples were taken only at the beginning and end of the experiment (Expt 1). The initial average OP was $290 \mathrm{mosmol} / \mathrm{kg}$, with a significant and linear effect of treatment on final plasma OP which increased with the amount of $\mathrm{NaCl}$ given $(297,302,329$ and $357 \mathrm{mosmol} / \mathrm{kg}$ (SE 7.2) for 300-OP, 340-OP, 380$\mathrm{OP}$ and $420-\mathrm{OP}$ respectively). Plasma solids showed a similar trend rising from initial values of $82 \cdot 3,83 \cdot 5,83 \cdot 5$ and $84.8 \mathrm{~g} / \mathrm{kg}$ to final values of $80 \cdot 3,83 \cdot 8,85 \cdot 3$ and $90 \cdot 0 \mathrm{~g} / \mathrm{kg}$ (SE 1.11) for 300-OP, 340-OP, 380-OP and 420-OP respectively, reflecting the mild dehydration of the animals subjected to the higher saline doses.

\section{DISCUSSION}

\section{Intragastric infusion and control of $O P$}

The use of animals maintained by intragastric infusion had the advantages that the model could be kept simple, pulse dosing with marker (Cr-EDTA) with rapid mixing allowing a number of measurements of volume to be made during the day. Furthermore, the rates of entry of VFA and of exogenous water into the rumen pool could be controlled, and kept constant. In a normally-fed animal, control of the entry of VFA at a constant rate is more difficult, and any confounding effects of OP on fermentation would have been unknown. In a pilot study we changed OP by varying the amount of buffer infused, but this also affected rumen $\mathrm{pH}$, and we wished as simple a model as possible and therefore chose $\mathrm{NaCl}$. Although there is evidence of $\mathrm{Na}-\mathrm{K}$ interactions in water flux into and out of the rumen (e.g. Scott, 1975), presumably these are due to differences in the flux of the ions involved and not to changes in OP affecting water flux. Warner \& Stacy (1972) did not find consistent differences in rumen water kinetics with the use of different solutes to raise OP. Since the main objective of the work was to study the effect of OP on rumen liquid outflow, we decided not to include $\mathrm{K}$-salts with the $\mathrm{NaCl}$.

\section{Rumen liquid kinetics}

Markers and modelling. The use of non-absorbable, water-soluble or -miscible markers enables estimates of rumen fluid volume, outflow and dilution rate. A limitation to the use of this type of marker is that it is not possible to separate the contributions of water movement across the epithelium and of saliva flow to the total flux of water through the rumen.

The mathematical model used in the present study is similar to that used by Hydén (1961) and by Warner \& Stacy (1968), and has been used extensively in experiments concerned with rumen fluid dynamics. Recently, France et al. (1991) reviewed the use of different models with an emphasis on the underlying assumptions and practical limitations of each. The main limitation of the model used in this work is that it assumes that the rumen pool 
Table 7. Matrix of linear correlation coefficients (r) between osmotic pressure, $p H$ and volatile fatty acid (VFA) concentration in the rumen, and the variables defining the water kinetics and $V F A$ absorption in the rumen in sheep

(Unless otherwise stated values from both experiments were combined, so $n 32 *$ (four animals $\times$ four periods $\times$ two experiments)

\begin{tabular}{|c|c|c|c|}
\hline & $\begin{array}{l}\text { Osmotic } \\
\text { pressure }\end{array}$ & $\mathrm{pH}$ & $\begin{array}{l}\text { Rumen VFA } \\
\text { concentration }\end{array}$ \\
\hline $\mathrm{pH}$ & -0.678 & & \\
\hline Rumen VFA concentration & $0.298 \dagger$ & $-0.337 \dagger$ & \\
\hline Rumen volume & 0.445 & 0.084 & $-0.119+$ \\
\hline Fractional outflow rate & $0 \cdot 365$ & -0.687 & $0.458+$ \\
\hline Liquid outflow rate & 0.539 & -0.716 & $0 \cdot 307 \dagger$ \\
\hline Net flux of liquid across the rumen wall & $0 \cdot 508$ & 0.697 & $-0.299 \dagger$ \\
\hline VFA absorption & $-0.497 \dagger$ & $0.369+$ & $0 \cdot 548 \dagger$ \\
\hline
\end{tabular}

$* P<0.05$ if $r \geqslant 0.349$ and $P<0.01$ if $r \geqslant 0.449$.

$\dagger$ Only Expt 2, so $n 16$. Then $P<0.05$ if $r \geqslant 0.497$ and $P<0.01$ if $r \geqslant 0.623$.

is in steady-state at the time of sampling and between two consecutive sampling times. This implies ideal conditions, and in practice there were differences between rumen volumes estimated at two consecutive sampling times.

Therefore, a model was tested in which liquid outflow and VFA absorption were corrected for changes in the rumen pools of PEG and VFA (calculated from the pulsedosed $\mathrm{Cr}$-EDTA) as observed between two consecutive sampling times, using the following equations:

$$
F^{\prime}=\frac{Q_{t_{i-1}}-Q_{t_{i}}}{P E G\left(t_{i}-t_{i-1}\right)}+F,
$$

where $Q_{t i}$ and $Q_{t i-1}$ are the quantities of PEG in the pool at times $t_{i}$ and $t_{i-1}$ respectively, and

$$
A^{\prime}=\frac{V F A_{t_{i}}-V F A_{i_{i-1}}}{t_{i}-t_{i-1}}+A,
$$

where $V F A_{t i}$ and $V F A_{i i-1}$ are the total amounts of VFA in the rumen at times $t_{i}$ and $t_{i-1}$ respectively.

This model is not restricted to steady-state conditions for it takes into account the changes in rumen volume (or VFA quantities) estimated at consecutive sampling times. However, although theoretically valid, we found it not to be suitable in practice when applied to our results. Errors in the estimation of PEG or VFA concentrations due to analytical and sampling errors were amplified in the successive steps of the model and resulted in large variability between and within animals sometimes giving outflows greater than the rumen volume, or 'negative' flows: therefore, this model was abandoned.

Rumen volume. Although differences between treatments in rumen volume were large in both experiments, the level of statistical significance of such differences was not the same in Expts 1 and 2 as a result of the high variability between animals in the values of this variable. The linear correlation coefficient between rumen volume and OP (Table 7 ) was not very high, although there was a clear trend for rumen volume to increase when OP was higher, owing to the accumulation of water to alleviate the high OP in the rumen contents. It seems, however, that the main effect of OP is on the rate and extent at which water enters 


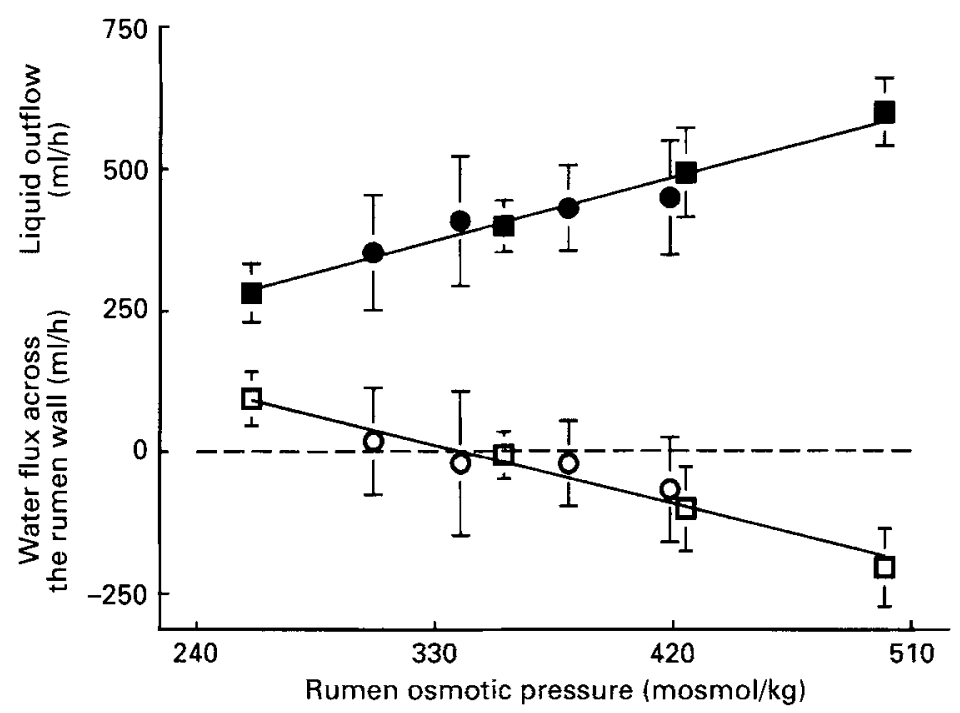

Fig. 1. The influence of the osmotic pressure in the rumen on liquid outflow ( $\mathbf{G}, \mathbf{O}$ ) and on the movement of water across the rumen wall $(\square, O)$. Each point represents the overall mean observed for each osmotic pressure, with the standard error of all the observations recorded for that treatment. The lines plotted are the calculated regression lines when data from $\operatorname{Expt} 1(\mathbf{O}, 0)$ and Expt $2(\boldsymbol{\square}, \square)$ were combined. For details of procedures, see pp. 154-157.

or leaves the rumen pool through the different pathways rather than on the absolute size of the rumen pool itself.

Partitioning between water outflow and absorption. Both experiments showed a linear effect of OP on the outflow of liquid from the rumen, and since the rate of liquid infusion was very similar the results of both experiments reported here were combined, demonstrating a linear and highly significant $(P<0.001)$ relationship between OP and liquid outflow (Fig. 1), in agreement with other reported observations in normally fed animals in which the addition of PEG (Harrison et al. 1975) or mineral salts (Thomson et al. 1978; Rogers \& Davis, 1982; Hart \& Polan, 1984), or the inclusion of a high-concentrate diet (Peters et al. 1990) increased both rumen fluid OP and rumen dilution rate. With our results the relationship between OP $(\mathrm{mosmol} / \mathrm{kg})$ and rumen outflow $(F ; \mathrm{ml} / \mathrm{h})$ was given by the equation:

$$
F=1.24 \text { OP }(\text { SE } 0.096)-36.5\left(\text { SE 36.6), } r^{2} 0.96 ; n 8 .\right.
$$

Similarly, water absorption from the rumen, calculated as the difference between infusion and outflow, was also well correlated with OP, and the relationship between OP $(\mathrm{mosmol} / \mathrm{kg})$ and water absorption $(W ; \mathrm{ml} / \mathrm{h})$ was given by:

$$
W=395\left(\text { SE 39.9) - 1.16 OP (SE 0.105), } r^{2} 0 \cdot 95 ; n 8\right. \text {. }
$$

This equation implies that for lower OP values there is an apparent absorption of water from the rumen, and as the rumen contents become hypertonic, water movement across the rumen wall is redirected towards the rumen lumen. As Fig. 1 shows, in the range of OP used in the two experiments water absorption was mostly negative, that is there was a net flux into the rumen from the plasma. The same kind of relationship between $O P$ and water movement through the rumen wall has been observed in studies conducted in normally fed animals fasting on experimental days (Warner \& Stacy, 1972), in rumen pouches (Engelhardt, 1970) or in the temporally isolated and washed rumen (Dobson et al. 1970; 
Engelhardt, 1970; Tabaru et al. 1990). The value of $341 \mathrm{mosmol} / \mathrm{kg}$ (SE 6.82) when the net flux was zero is slightly above the range of $265-325 \mathrm{mosmol} / \mathrm{kg}$ suggested by Engelhardt (1970) based on work with rumen pouches, and is within the ranges observed by the same author in the temporally isolated rumen $(260-340 \mathrm{mosmol} / \mathrm{kg}$ ) and by Warner \& Stacy (1972) in normally fed animals (295-360 mosmol $/ \mathrm{kg}$ ). Net efflux and net influx could be observed at lower and higher OP respectively, but the rumen seemed not to be very permeable to water since the net extent of the transepithelial movement of water into or out of the rumen was not very high, in agreement with previous observations (Engelhardt, 1970; Warner \& Stacy, 1972).

Our calculations assume no saliva flow, although there was probably some saliva secretion. The effect of any saliva flow on the apparent relationship between OP and actual net water flux (corrected for saliva) would be to move the intercept at zero net flux (Fig. 1) to a higher OP. For example, correction for a saliva flow of $42 \mathrm{ml} / \mathrm{h}$ (equivalent to $11 / \mathrm{d}$ ), constant at all OP, would increase the OP for zero net flux to $376 \mathrm{mosmol} / \mathrm{kg}$. Therefore, our value of $341 \mathrm{mosmol} / \mathrm{kg}$ for zero flux implies a small flow of saliva, as would be expected in animals that seldom chew or ruminate, and with their rumen contents buffered. This discussion has assumed the relationship between net water flux and OP to be linear, similar to that reported by Warner \& Stacy (1972). However, Engelhardt (1970), using data derived from rumen pouches, suggested a relationship more sigmoid than linear, with little net flux over a range of OP close to that of plasma. Fig. 1 would suggest that our results may also have conformed to this model.

Thus, rumen $O P$ is an important factor affecting water flow into and out of the rumen. With our results it is not possible to separate both components of this flow, namely saliva secretion and exchanges across the rumen wall. However, it seems that OP per se does not affect the salivary contribution since salivary secretion rate is inversely related to plasma osmolality (Warner \& Stacy, 1977; Silanikove \& Tadmor, 1989; Carter \& Grovum, 1990), and the parasympathetic activity, which regulates and stimulates salivary glands, is reduced by increased osmolality of venous blood (Carr, 1984). Therefore, the change in water flow into the rumen mediated by changes in rumen OP should mainly be due to the transfer of water across the rumen wall, and the main force governing it would be the gradient of osmolality between the rumen contents and the blood perfusing the rumen epithelium (Dobson, 1984). Any increase in rumen OP is followed by an increase in blood OP, which seems to activate the blood flow in the ruminal mucosa affecting water movement through epithelium (Dobson et al. 1976).

Thus, the net effect of an increasing OP is to change the partitioning of water loss from the rumen towards outflow to the omasum by reducing absorption, even to a negative absorption when OP is much above that of plasma. With the higher OP there was the suggestion that the liquid outflow rate may have reached a peak by $6.5-8 \mathrm{~h}$ (Table 3 ). This trend, together with the fact that rumen volume tended to increase at higher OP (Table 2), would suggest that there may be a maximal liquid outflow regulated by the reticulo-omasal orifice, which would control the amount leaving the rumen. Moir (1984) suggested that an important function of the omasum could be to 'meter' digesta flow to the abomasum, and to absorb VFA and buffer, thus acting as '... an homeostatic device in relation to gastric secretory function, and possibly as an energy-conserving mechanism for reducing the amount of gastric $\mathrm{HCl}$ produced'. The rumen contents of sheep nourished by intragastric infusions are entirely liquid, and yet outflow is not unconstrained as shown by the fact that rumen volume increased with OP. Similarly, we (F. D. DeB. Hovell \& N. A. MacLeod, unpublished results) have noticed in the management of animals nourished by intragastric nutrition the importance of maintaining a low rumen OP to prevent the rumen becoming 'overfull' (Hovell et al. 1987). Thus, it would seem that the omasum does in some way 
control the flow of digesta from the rumen possibly by means of changing the omasal orifice. A possible mechanism could be by means of osmoreceptors in the omasum acting as sensors.

Although net absorption of liquid occurs in the hypotonic rumen, as OP increases this is reduced and increasingly water leaves the rumen by passage to lower parts of the digestive tract. This water has to be absorbed post-ruminally and recycled, otherwise the animal would be dehydrated in a few hours. First, increasing the flow of digesta through the omasum, absorption of VFA and $\mathrm{Na}$ is increased markedly, as is omasal water absorption (Engelhardt \& Hauffe, 1975; Edrise et al. 1986). Second, the absorption of gut water is necessary to attenuate the rise in blood plasma osmolality and as a defence mechanism against dehydration (Silanikove \& Tadmor, 1989). If the animal does not reduce rumen OP by drinking then recycling across the rumen wall to the lumen could help to alleviate the detrimental effects of a high rumen OP. However the influx of water can damage the rumen epithelium since the high hydrostatic pressure applied to the propia mucosae produces vesicles by detaching layers of the rumen wall (Engelhardt, 1970). We have noticed (F. D. DeB. Hovell \& N. A. MacLeod, unpublished results) that with animals nourished by intragastric nutrition, rumen OP values in excess of $450-500 \mathrm{mosmol} / \mathrm{kg}$ can result in substantial shedding of what appears to be epithelial debris into the rumen. When this occurs the infusion rate of VFA has to be reduced for several days, since absorption appears to be inhibited. We have interpreted this in the context of a hydrostatically induced shedding as described above, and have speculated that damage to the rumen epithelium associated with the acidosis sometimes induced by feeding large amounts of starchy concentrates to normally fed animals is initiated by high OP rather than by low $\mathrm{pH}$. This would support the observations of Ahrens (1967), who added hypertonic sodium lactate to the rumen of cattle and noted damage to the epithelium.

Although the influx of water into the rumen through the rumen epithelium induced by increasing rumen $O P$ seems not to be quantitatively very high, its direct effect on the liquid outflow rate from the rumen could have important nutritional consequences in the normally fed animal. It is possible that as the liquid outflow rate is increased more undegraded particles in the rumen contents will be washed out of the rumen, leading to a reduction in rumen fill and a resulting increase in food intake. Results reported by Ullyatt et al. (1984) seem to confirm this assumption, while Harrison et al. (1975) have suggested that such an increase in the flow of digesta to the duodenum would increase the efficiency of microbial synthesis in the rumen, and so increase the flow of protein and starch to the duodenum.

\section{$V F A$ absorption}

As can be seen from Table 7, the correlation between VFA absorption and rumen OP was significant $(P<0 \cdot 05)$, although only one-quarter of the variance $\left(r^{2} 0 \cdot 25\right)$ could be explained by the relationship, mainly because our results seem to indicate that the VFA absorption may have been optimal when rumen OP was about $350 \mathrm{mosmol} / \mathrm{kg}$ when the net flux of water into the rumen was almost nil. However, of the total VFA infused the proportion absorbed was $0.874,0.845,0.794$ and 0.714 (SED 0.0299) as OP was increased, indicating that the linear decline in VFA absorption was highly significant $(P<0.001)$. VFA absorption was significantly $(P<0.01)$ correlated with net water flux $(r 0.669, n 16)$, and as liquid outflow increased an increasing proportion of the VFA leaving the rumen left with it. It is interesting that at the higher OP values, VFA continued to be absorbed against the hydrostatic pressure. Engelhardt \& Hauffe (1975) showed VFA (plus $\mathrm{Na}$ and K) absorption from the omasum to be linearly related to water absorption. Water absorption was always positive unlike our observations on net flux through the rumen wall. 
However, water molecules would have been passing in both directions and absorption might have been related to the true flux into the plasma. Whatever the reason, however, the effect of the net influx of water across the rumen epithelium with the higher OP values was to hinder VFA absorption in a pattern similar to that reported by Oshio \& Tahata (1984) and Tabaru et al. (1990).

The molar proportions of VFA absorbed were also affected by the change in rumen OP, with the absorption rates of propionate and butyrate increasing and that of acetate decreasing. This may have been $\mathrm{pH}$ related because the accumulation of VFA in the rumen tended to reduce rumen $\mathrm{pH}$ (Table 4), thus favouring the absorption of the longer-chain fatty acids (Danielli et al. 1945; Stevens, 1970).

S. L. is grateful for the concession of a post-doctoral fellowship by the Spanish Comision Interministerial de Ciencia y Tecnología (C.I.C.Y.T.). The authors wish to thank Ms M. Moran and $\mathrm{Mr}$ J. Morrison for the analytical work for VFA determinations, Dr $\mathbf{M}$. Franklin for his help with the statistical methods, Dr J. France for his advice on the mathematical modelling and $\mathrm{Mr} \mathrm{D}$. Kyle for skilled technical help. Financial support for this work was in part provided by the Agriculture and Fisheries Department of the Scottish Office.

\section{REFERENCES}

Ahrens, F. A. (1967). Histamine, lactic acid and hypertonicity as factors in the development of rumenitis in cattle. American Journal of Veterinary Research 28, 1335-1342.

Carr, D. H. (1984). The regulation of parotid and submaxillar salivary secretion in sheep. Quarterly Journal of Experimental Physiology 69, 587-597.

Carter, R. R. \& Grovum, W. L. (1990). A review of the physiological significance of hypertonic body fluids on feed intake and ruminal function: salivation, motility and microbes. Journal of Animal Science 68, 2811-2832.

Danielli, J. R., Hitchcock, M. W. S., Marshall, R. A. \& Phillipson, A. T. (1945). The mechanism of absorption from the rumen as exemplified by the behaviour of acetic, propionic and butyric acids. Journal of Experimental Biology' 22, 75-84.

Dobson, A. (1984). Blood flow and absorption from the rumen. Quarterly Journal of Experimental Physiology 69 , $599-606$.

Dobson, A., Sellers, A. F. \& Shaw, G. T. (1970). Absorption of water from isolated ventral sac of rumen of the cow. Journal of Applied Physiology 28, 100-124.

Dobson, A., Sellers, A. F. \& Gatewood, V. H. (1976). Absorption and exchange of water across rumen epithelium. American Journal of Physiology 231, 1588-1594.

Downes, A. M. \& McDonald, I. W. (1964). The chromium-51 complex of ethylene diamine tetracetic acid as a soluble rumen marker. British Journal of Nutrition 18, 153-162.

Edrise, B. M., Smith, R. H. \& Hewitt, D. (1986). Exchanges of water and certain water-soluble minerals during passage of digesta through the stomach compartments of young ruminating bovines. British Journal of Nutrition $55,157-167$.

Engelhardt, W. v. (1970). Movement of water across the rumen epithelium. In Physiology of Digestion and Metabolism in the Ruminant, pp. 132-146 [A. T. Phillipson, editor]. Newcastle-upon-Tyne: Oriel Press.

Engelhardt, W. v. \& Hauffe, R. (1975). Role of the omasum in the absorption and secretion of water and electrolytes in sheep and goats. In Digestion and Metabolism in the Ruminant, pp. 216-230 [I. W. McDonald and A. C. I. Warner, editors]. Armidale: University of New England Publishing Unit

Faichney, G. J. \& Boston, R. C. (1985). Movement of water within the body of sheep fed at maintenance under thermoneutral conditions. Austratian Journal of Biological Science 38, 85-94.

France, J., Siddons, R. C., Dhanoa, M. S. \& Thornley, J. H. M. (1991). A unifying mathematical analysis of methods to estimate rumen volume using digesta markers and intraruminal sampling. Journal of Theoretical Biology 150, 145-155.

Harrison. D. J., Beever, D. E., Thomson, D. J. \& Osbourn, D. F. (1975). Manipulation of rumen fermentation in sheep by increasing the rate of flow of water from the rumen. Journal of Agricultural Science, Cambridge $\mathbf{8 5}$, 93-101.

Hart, S. P. \& Polan, C. E. (1984). Effect of sodium bicarbonate and disodium phosphate on animal performance, ruminal metabolism, digestion, and rate of passage in ruminating calves. Journal of Dairy Science 67, 2356-2368

Hovell, F. D. DeB., Ørsksov, E. R., Kyle, D. J. \& MacLeod, N. A. (1987). Undernutrition in sheep. Nitrogen repletion by $\mathrm{N}$-depleted sheep. British Journal of Nutrition $\mathbf{5 7}, 77-88$. 
Hydén, S. (1956). A turbidimetric method for the determination of higher polyethylene glycols in biological materials. Annals of the Royal Agricultural College of Sweden 22, 131-145.

Hydén, S. (1961). Determination of the amount of fluid in the reticulo-rumen of the sheep and its rate of passage to the omasum. Annals of the Royal Agricultural College of Sweden 27, 51-79.

Moir, R. J. (1984). Why an omasum? In Ruminant Physiology-Concepts and Consequences, pp. 85-92. [S. K. Baker, J. M. Gawthorne, J. B. Mackintosh and D. B. Purser, editors]. Perth: School of Agriculture, University of Western Australia.

Ørskov, E. R., Grubb, D. A., Wenham, G. \& Corrigall, W. (1979). Sustenance of growing and fattening ruminants by intragastric infusion of volatile fatty acid and protein. British Journal of Nutrition 41, 553-558.

Oshio, S. \& Tahata, I. (1984). Absorption of dissociated volatile fatty acids through the rumen wall of sheep. Canadian Journal of Animal Science 64 (Suppl.), !67-168.

Ottenstein, D. M. \& Bartley, D. A. (1971). Separation of free acids $C_{2}-C_{5}$ in dilute aqueous solution column technology. Journal of Chromatographic Science 9, 673-681.

Peters, J. P., Paulissen, J. B. \& Robinson, J. A. (1990). The effects of diet on water flux and volatile fatty acid concentration in the rumen of growing beef steers fed once daily. Joumal of Animal Science 68, 1711-1718.

Rogers, J. A. \& Davis, C. L. (1982). Effects of intraruminal infusions of mineral salts on volatile fatty acid production in steers fed high-grain and high-roughage diets. Journal of Dairy Science 65, 953-962.

Rowell, J. G. \& Walters, D. E. (1976). Analyzing data with repeated observations on each experimental unit. Journal of Agricultural Science, Cambridge 87, 423-432.

Scott, D. (1975). Changes in mineral, water and acid-base balance associated with feeding and diet. In Digestion and Metabolism in the Ruminant, pp. 205-215 [I. W. McDonald and A. C. I. Warner, editors]. Armidale: University of New England Publishing Unit.

Silanikove, N. \& Tadmor, A. (1989). Rumen volume, saliva flow rate, and systematic fluid homeostasis in dehydrated cattle. American Journal of Physiology 256, R809-R815.

Stevens, C. E. (1970). Fatty acid transport through the rumen epithelium. In Physiology of Digestion and Metabolism in the Ruminant, pp. 101-112 [A. T. Phillipson, editor]. Newcastle-upon-Tyne: Oriel Press.

Tabaru, H., Ikeda, K., Kadota, E., Marukami, Y., Yamada, H., Sasaki, M. \& Takeuchi, A. (1990). Effects of osmolality on water, electrolytes and volatile fatty acids absorption from the isolated ruminoreticulum in the cow. Japanese Journal of Veterinary Science, Tokyo 52, 91-96.

Thomson, D. J., Beever, D. E., Latham, M. J., Sharpe, M. E. \& Terry, R. A. (1978). The effect of inclusion of mineral salts in the diet on dilution rate, the pattern of rumen fermentation and the composition of the rumen microflora. Journal of Agricultural Science, Cambridge 91, 1-7.

Ullyatt, M. J., Waghorn, G. C., John, A., Reid, C. W. S. \& Monro, J. (1984). Effect of intake and feeding frequency on feeding behaviour and quantitative aspects of digestion in sheep fed chaffed lucerne hay. Journal of Agricultural Science, Cambridge 102, 645-657.

Warner, A. C. I. \& Stacy, B. D. (1968). The fate of water in the rumen. 1. A critical appraisal of the use of soluble markers. British Joumal of Nutrition 22, 369-387.

Warner, A. C. I. \& Stacy, B. D. (1972). Water, sodium and potassium movements across the rumen wall of sheep. Quarterly Journal of Experimental Physiology 57, 103-119.

Warner, A. C. I. \& Stacy, B. D. (1977). Influence of ruminal and plasma osmotic pressure on salivary secretion in sheep. Quarterly Journal of Experimental Physiology 62, 133-142. 